This item was submitted to Loughborough's Research Repository by the author.

Items in Figshare are protected by copyright, with all rights reserved, unless otherwise indicated.

\title{
Journeys in mathematical landscapes: genius or craft?
}

PLEASE CITE THE PUBLISHED VERSION

PUBLISHER

Springer

VERSION

AM (Accepted Manuscript)

PUBLISHER STATEMENT

The final authenticated version is available online at https://doi.org/10.1007/978-3-030-28483-1_9.

LICENCE

CC BY-NC-ND 4.0

REPOSITORY RECORD

Lane, Lorenzo, Ursula Martin, Dave Murray-Rust, Alison Pease, and Fenner Tanswell. 2019. “Journeys in Mathematical Landscapes: Genius or Craft?”. figshare. https://hdl.handle.net/2134/9487880.v1. 


\title{
Journeys in mathematical landscapes: genius or craft?
}

\section{Lorenzo Lane}

\section{Ursula Martin, University of Oxford ${ }^{1}$}

Dave Murray-Rust, University of Edinburgh

\author{
Alison Pease, University of Dundee \\ Fenner Tanswell, University of St Andrews
}

\begin{abstract}
We look at how Anglophone mathematicians have, over the last hundred years or so, presented their activities using metaphors of landscape and journey. We contrast romanticised self-presentations of the isolated genius with ethnographic studies of mathematicians at work, both alone, and in collaboration, looking particularly at on-line collaborations in the "polymath" format. The latter provide more realistic evidence of mathematicians daily practice, consistent with the the "growth mindset" notion of mathematical educators, that mathematical abilities are skills to be developed, rather than fixed traits.

We place our observations in a broader literature on landscape, social space, craft and wayfaring, which combine in the notion of the production of mathematics as crafting the exploration of an unknown landscape. We indicate how "polymath" has a two-fold educational role, enabling participants to develop their skills, and providing a public demonstration of the craft of mathematics in action.
\end{abstract}

\section{Section 1 Prelude}

In 1993 Andrew Wiles announced the proof of Fermat's Last Theorem. A subsequent interview by the US PBS [Wiles, 2000] plays to the popular notion of a lone genius, waiting for inspiration to strike, and highlights the "passion and emotion" of mathematics, lingering on the moment where Wiles says

And sometimes I realized that nothing that had ever been done before was any use at all. Then I just had to find something completely new; it's a mystery where that comes from,

followed by a dramatic pause.

\footnotetext{
${ }^{1}$ Corresponding author: Ursula.Martin@maths.ox.ac.uk
} 
Mathematical genius and creativity have received much attention [Robinson 2011]. Yet the interview also highlights more day-to-day aspects of mathematicians' work, which in this paper we designate as the "craft" of mathematics, as in the paragraph immediately preceding the quote above

I used to come up to my study, and start trying to find patterns. I tried doing calculations which explain some little piece of mathematics. I tried to fit it in with some previous broad conceptual understanding of some part of mathematics that would clarify the particular problem I was thinking about. Sometimes that would involve going and looking it up in a book to see how it's done there. Sometimes it was a question of modifying things a bit, doing a little extra calculation.

These small explorations form part of a larger whole, cast as exploring an unknown landscape: Perhaps I can best describe my experience of doing mathematics in terms of a journey through a dark unexplored mansion. You enter the first room of the mansion and it's completely dark. You stumble around bumping into the furniture, but gradually you learn where each piece of furniture is. Finally, after six months or so, you find the light switch, you turn it on, and suddenly it's all illuminated. You can see exactly where you were. Then you move into the next room and spend another six months in the dark. So each of these breakthroughs, while sometimes they're momentary, sometimes over a period of a day or two, they are the culmination of - and couldn't exist without - the many months of stumbling around in the dark that proceed them.

This notion of "stumbling" inspired a previous paper [Martin, 2015], where online and computational mathematics were analysed to shed light this fine-grained mathematical practice of the craft of mathematics.

This paper is an initial study of this craft, attempting to reconcile the contrasting notions of genius and craft through viewing the mathematician as crafting a journey through a mathematical landscape, with mathematical education providing wayfarer with the necessary skills and tools. We look first, in Section 2, at mathematicians' metaphors of journeys in space; then in Section 3 give an initial indication of how these might be framed in terms of literary studies, social science and philosophy, suggesting that ideas of explorations of a fixed landscape might be broadened to consider how mathematicians themselves create that landscape. In Section 4 we contrast such notions of genius and inspiration in traversing the landscape with notions of mathematics education as developing skills in the learner. In Section 5 we discuss the "polymath" online collaborations, a form of "social machine", and their use in mathematics education. In Section 6 we suggest how theories of craft, in particular Ingold's notion of crafting as wayfaring, open up new possibilities for framing the practice of mathematics, and shed further light on the educational role of polymath collaborations. 


\section{Section 2 Mathematicians on mathematics: the journey in space}

Newton's remark that

I know not what I may seem to the world, but as to myself, I seem to have been only like a boy playing on the sea-shore and diverting myself in now and then finding a smoother pebble or a prettier shell than ordinary, whilst the great ocean of truth lay all undiscovered before me. [Turnow, 1806], cited in [Schaffer, 2009, p. 243].

is often taken as the epitome of the lone mathematician exploring the natural world, and modestly presenting his (always his) activities to a small coterie of followers. Schaffer [Schaffer, 2009] observes that the remark, or alleged remark, only reported some years after Newton's death, is likely to have been taken up so that Newton's isolation and intellectual approach might add authority to his ideas. Newton worked among informants skilled in so-called "practical mathematics", the arithmetic and geometry needed for accounting, surveying, navigation and warfare, and a staple of education for anyone above the labouring classes. The nineteenth century saw this tradition somewhat at odds with the rise of abstraction in mathematical education and research, following more rigorous approaches emerging from Europe [Craik, 2016].

Augustus De Morgan, a celebrated educator in this newer more abstract tradition, writes in the 1842 preface to his influential (and monumental) calculus textbook [De Morgan, 1842] that

the way to enlarge the settled country [of mathematics] has not been by keeping within it, but by making voyages of discovery [De Morgan, 1842, p. vii]

and quotes Newton's supposed remark approvingly to his pupil Ada Lovelace [Hollings et al, 2017]

That which you say about the comparison of what you do with what you see can be done was equally said by Newton when he compared himself to a boy who had picked up a few pebbles from the shore ... so that you have respectable authority for supposing that you will never get rid of that feeling; and it is no use trying to catch the horizon [quoted in Hollings et al, 2017, p. 208; original in LB 170, 15 September 1840, f. 14r]

Such metaphors of exploration and colonisation are unsurprising for the time, and sat comfortably with sensibilities of later British mathematicians: Cambridge's G H Hardy, a keen climber himself, and friend of the climbers Mallory and Irving, who were lost attempting to scale Everest, wrote [Hardy, 1929]

I have myself always thought of a mathematician as in the first instance an observer, a man who gazes at a distant range of mountains and notes down his observations. His object is simply to distinguish clearly and notify to others as many different peaks as he can. There are 
some peaks which he can distinguish easily, while others are less clear. He sees A sharply, while of B he can obtain only transitory glimpses. At last he makes out a ridge which leads from A, and following it to its end he discovers that it culminates in B. [Hardy, 1929 p. 18]

Hardy extends this metaphor to reflect on the nature of proof:

B is now fixed in his vision, and from this point he can proceed to further discoveries. In other cases perhaps he can distinguish a ridge which vanishes in the distance, and conjectures that it leads to a peak in the clouds or below the horizon. But when he sees a peak he believes that it is there simply because he sees it. If he wishes someone else to see it, he points to it, either directly or through the chain of summits which led him to recognise it himself. When his pupil also sees it, the research, the argument, the proof is finished. [Ibid.]

Hardy's notion of education is striking to the modern reader: the pupil needs to see the result is true, but nothing is said about the process of learning to do proofs.

The analogy is a rough one, but I am sure that it is not altogether misleading. If we were to push it to its extreme we should be led to a rather paradoxical conclusion; that there is, strictly, no such thing as mathematical proof; that we can, in the last analysis, do nothing but point; that proofs are what Littlewood and I call gas, rhetorical flourishes designed to affect psychology, pictures on the board in the lecture, devices to stimulate the imagination of pupils. [Ibid.]

Gilbert Ryle takes the metaphor to the jungle, [Ryle, 1971]

the pioneering path-finder, Pythagoras say, has no tracks to follow ...through the jungle [ it may be that $]. .$. he will have made a track along which he can now guide docile companions safely and easily right through the jungle. How does he achieve this? Not by following tracks, since there are none to follow. Not by sitting down and wringing his hands. But by walking over ground where tracks certainly do not exist, but where, with luck, assiduity and judgement, tracks might and so perhaps will exist. All his walkings are experimental walkings on hypothetical tracks or candidate-tracks or could-be tracks, or tracks on appro; and it is by so walking that, in the end, while of course he finds lots and lots of impasses, he also finds (if he does find), a viable track. [Ryle, 1971 p. 224]

and the contemporary mathematician and author Marcus du Sautoy [du Sautoy, 2015], channelling Hardy, argues, with a nod to Tolkein, that:

A proof is like the mathematician's travelogue. Fermat gazed out of his mathematical window and spotted this mathematical peak in the distance, the statement that his equations do not 
have whole number solutions. The challenge for subsequent generations of mathematicians was to find a pathway leading from the familiar territory that mathematicians had already navigated to this foreign new land. Like the story of Frodo's adventures in Tolkien's Lord of the Rings, a proof is a description of the journey from the Shire to Mordor.

A successful proof is like a set of signposts that allow all subsequent mathematicians to make the same journey. Readers of the proof will experience the same exciting realisation as its author that this path allows them to reach the distant peak. Very often a proof will not seek to dot every i and cross every $t$, just as a story does not present every detail of a character's life. It is a description of the journey and not necessarily the re-enactment of every step. The arguments that mathematicians provide as proofs are designed to create a rush in the mind of the reader.

In recent years a number of mathematicians have written accounts of the discipline for the general reader, with the "landscape" metaphor remaining prominent. For 2010 Fields medallist Cedric Villani [Villani, 2015], whose book largely consists of transcriptions of emails sent as his work developed,

The complexity of the mathematical landscape ... makes my head spin [Villani, 2015, p. 80]

and he notes the role of analogy:

The ability to detect connections between different areas of mathematics is what has made my reputation. These connections are invaluable. It is a bit like a game of Ping-Pong: every discovery you make on one side helps you discover something new on the other. The connections make it possible to see more of the landscape on both sides. [Villani, 2015, p. $135]$

Michael Harris [Harris, 2010], in a wide-ranging account of the mathematical process, draws on the more contemporary analogy of video-games, in describing the sense of being an avatar in the virtual world, while John Conway [Roberts, 2015] graphically describes the physicality of the geometrical worlds he is investigating:

For a time I was thinking so geometrically about these things that I used to imagine myself with lots and lots of arms and legs, extra limbs. Because if I have two arms and point 'em out, then they both lie in a plane. And I'll use a leg as well, and now they are lying in threedimensional space. To form an adequate idea, an adequate geometric visualisation, of what is going on in 24 dimensions is more or less impossible. In large dimensional space, there are large numbers of directions to point, so you would seem to need quite a lot of arms and legs. I distinctly remember imagining myself stuck in the middle of this space, and waving all my 
arms and legs in the air, and trying to understand things, looking up at the stars, pretending they are the lattice points, and just sort of daydreaming.

\section{Section 3 The journey in space: broader reflections}

Such metaphors have been cast more broadly by authors in philosophy, social science, sociology of knowledge and literary theory. Alice Jenkins [Jenkins, 2007] unpicks approaches to understanding and categorisation of the "spaces" and "landscapes" of knowledge, from the Romantic movement in literature onwards. As Jenkins observes,

the same kinds of mental processes that allow us to perceive the organization of a landscape are analogous to the ones that allow us to perceive the organization of a body of knowledge ... strategies used to regulate access to knowledge and to manage the twin pulls towards spread and containment of information. [Jenkins, 2007 p. 7]

These metaphors can be construed as the manifestation of relations of class, power and colonialism:

Some of these strategies involved use of spatial metaphor, for instance by imagining knowledge as a landscape in which certain kinds of journeys and certain kinds of traveller were permitted and others excluded. [Ibid.]

Lane [Lane, 2015] draws on Bourdieu [Bourdieu, 1985] and Sewell [Sewell, 1992] in interpreting substantial ethnographic observation to show how mathematical perception is built up from the domains of physical, conceptual and discourse space. Bourdieu sees such categorizations as the manifestations of the social world [Bourdieu, 1985], and Lane argues that the crafting of ideas changes as a function of space, these spaces being socially determined. These domains share schemas which are mobilised during problem solving and proof construction, to guide mathematicians' intuitions; and are utilised during communicative acts, in order to create common ground and common reference frames. Different structuring principles are utilised according to the contexts in which the act of knowledge production or communication take place. Lane argues further that the degree of formality, privacy or competitiveness of environments affects the presentation of mathematicians' selves and ideas, and that mathematicians' perceptions of mathematical phenomena are dependent upon their positions and relations in this "social space".

Metaphors are important. These mathematicians present mathematics as a fixed Platonic landscape, open to conquest and colonisation by intrepid mathematician-explorers, who show others the paths they have made and the things they have discovered. To join them the pupils too have to be fearless and intrepid: and little is said about how to learn the skills of exploration. 
Yet the approach of sociologists opens up the question of how the mathematicians themselves might be creating that landscape, and what skills that might require. It is beyond our scope here to look at broader philosophical issues, for example the contrast between mathematics as theory-building, and mathematics as problem-solving, as in Gowers [Gowers, 2010]. But mathematicians themselves can sometimes question if landscape metaphors are too constraining: for example Jim Propp, quoted in [Roberts, 2015], wonders if John Conway:

is the rare sort of mathematician whose ability to connect his pet mathematical interests makes one wonder if he isn't, at some level, shaping mathematical reality and not just exploring it. The example of this that I know best is a connection he discovered between sphere packing and games. These were two separate areas of study that Conway had arrived at by two different paths. So there's no reason for them to be linked. But somehow, through the force of his personality, and the intensity of his passion, he bent the mathematical universe to his will. [Roberts, 2015, p. 2]

The account by Ehrhardt [Ehrhardt, 2010] of the work of Evariste Galois gives a nice example of how such apparently fixed landscapes can be both post-hoc constructions, ways of organising knowledge, as indicated by Jenkins; and be shaped by social as well as scientific forces as indicated by Bourdieu and Lane. Galois's work on the solution of equations was dismissed by Poisson and Lacroix, and his contribution was only recognised once later mathematicians had developed the theory of equations in a broader context. As Ehrhardt remarks:

Indeed, the meaning of a mathematical text is the product of a long social and scientific process, one that, in the case of Galois's text, took over one hundred years. During this long period, Galois's text was read, interpreted and recast by a large number of actors who did not agree as to its meaning and mostly construed it through local lenses. Only at the beginning of the 20th century, when Galois theory entered the realm of teaching in European countries, did it acquire a more unified meaning.

A further philosophical aspect beyond our scope is that of the aesthetic of mathematics: the philosopher Robert Thomas [Thomas, 2016] offers a different metaphor for the choices a mathematician makes in shaping the landscape:

Much mathematical effort is more like landscape gardening than like picture drawing. I take picture drawing to begin with a blank sheet ... Mathematical creation is not so free, hence the contrasting analogy of the landscape gardener, who needs a good grasp of the topography before getting down to creating something beautiful [Thomas, 2016, p. 124]

\section{Section 4 Mathematicians on mathematics: genius versus craft}


Yet, while such metaphors of journeys of discovery in a space of mathematical possibilities are widespread, much less attention is paid in such popular writing on mathematics to the practice of mathematics. While Wiles's presentation of the messy day-to-day business mathematicians' work, above, as "stumbling around in the dark", seems credible, for others there is a more idealistic view. For du Sautoy [du Sautoy, 2015] such practice is seemingly about a world of choices based on narrative impact:

When I am creating a new piece of mathematics the choices I will make will be motivated by the desire to take my audience on an interesting mathematical journey full of twists and turns and surprises. I want to tease an audience with the challenge of why two seemingly unconnected mathematical characters should have anything to do with each other. And then as the proof unfolds there is a gradual realisation or sudden moment of recognition that these two ideas are actually one and the same character.

Roberts [Roberts, 2015], while acknowledging that her subject is an unreliable narrator, makes light of the labour of one of Conway's major discoveries:

Conway had expected to keep to his house-arrest work ethic for weeks or months or beyond. Locking himself away that first Saturday, he unfurled an unused roll of wallpaper backing paper and sketched out all he knew about the problem. By that very evening, he'd figured it out. He'd deduced the Leech lattice's number of symmetries.

Such unrealistic representations play to the further self-presentation of the mathematician as an idiosyncratic genius possessed of an indefinable charisma: an observant account is presented by Michael Harris in his book Mathematics without Apologies [Harris, 2015]. Harris frames such mathematical charisma, including his own, by quoting Bourdieu:

The charismatic leader manages to be for the group what he is for himself, instead of being for himself, like those dominated in the symbolic struggle, what he is for others. He 'makes' the opinion which makes him; he constitutes himself as an absolute by a manipulation of symbolic power which is constitutive of his power since it enables him to produce and impose his own objectification. [Bourdieu, 1984, p 208]

It is beyond our scope to consider in detail how such self-perpetuating acculturation influences all aspects of the doing of mathematics: not just the public perception of mathematics, or how people become mathematicians, or the career and prestige of individuals, but also choice and acceptability of problems, and credibility of proposed proofs.

A striking example is provided by the discussion by leaders of the field, on Frank Calegari's wellrespected blog [Calegari, 2017], of the recent claims by Mochizuki to have proved the long-standing 
$\mathrm{ABC}$ conjecture. Mochizuki's claims, because of his previous work, or "charisma", initially carried some credibility. Doubts increased, due to the difficulty in understanding the papers, his disinclination to present the work in public, and reports that it was to be published in a journal of which he is himself the editor. Terence Tao pointed out how unusual it was that the lengthy development did not contain within it a "proof of concept" - a smaller result which would give the reader some confidence in the direction of travel [Tao, 2017]

It seems bizarre to me that there would be an entire self-contained theory whose only external application is to prove the abc conjecture after $300+$ pages of set up, with no smaller fragment of this setup having any non-trivial external consequence whatsoever.

Tanswell [Tanswell, 2017] proposes framing this debate in terms of the philosophical theory of mathematical "virtues", identifying a tension between Mochizuki's defence of the rigour of his collaborators, the expectation of the virtues of significant labour and humility on the part of even his expert readers, and the expectation of those readers of the virtues of transparency and clarity and links to other mathematical material. Tanswell's "Moderate Proposal" is that virtues and vices of mathematicians are relevant to mathematical knowledge, and virtues, vices and values can be incorporated more generally into philosophy of mathematics. Mason and Hanna [Mason, 2016] extend this to education, identifying the tension between values of care for students, and care for mathematics, in choices of expository style.

Thus valuable and credible as the reflections of mathematicians are, in shedding light on controversies in mathematics, and how practitioners think about their own discipline, they still tell us less about the "how" of doing mathematics, or of learning how to do mathematics. Indeed, by reinforcing stereotypes of the mathematician as an inspired genius, and mathematics as a competitive sport, they contribute to a perception of mathematical ability as a fixed trait. This view has been strongly challenged by researchers in mathematical education, notably Dweck [Dweck 2006] and Boaler [Boaler 2016], who argue that such a "fixed mindset", seeing mathematical ability as unusual and unchangeable, hampers student learning, and that achievement increases when students shift to a "growth mindset" of believing that their abilities can be developed and their intelligence is malleable.

Terry Tao, a Fields medallist and respected mentor, teacher and mathematical innovator, who was himself a child prodigy, makes similar points. A prolific blogger on education, his 2007 blog post against the notion of genius forcefully presents mathematical ability as a skill to be learned:

Does one have to be a genius to do mathematics? 
The answer is an emphatic NO. In order to make good and useful contributions to mathematics, one does need to work hard, learn one's field well, learn other fields and tools, ask questions, talk to other mathematicians, and think about the "big picture". And yes, a reasonable amount of intelligence, patience, and maturity is also required. But one does not need some sort of magic "genius gene" that spontaneously generates ex nihilo deep insights, unexpected solutions to problems, or other supernatural abilities. [Tao, 2007] concluding, in the spirit of amassing "capital" in the form of understanding and contributions to a collective effort, but at odds with Harris's more flamboyant notions of "charisma", that

It's also good to remember that professional mathematics is not a sport (in sharp contrast to mathematics competitions). The objective in mathematics is not to obtain the highest ranking, the highest "score", or the highest number of prizes and awards; instead, it is to increase understanding of mathematics (both for yourself, and for your colleagues and students), and to contribute to its development and applications. For these tasks, mathematics needs all the good people it can get. [Ibid.]

The tools of ethnography, and the emerging field of "mathematical practice", give a more realistic account of the day to day activities of mathematicians.

Ethnographers observe mathematicians' day to day activity, alone and with others, on notepads and blackboards, as they strive to understand and develop ideas [Barany, 2014]:

We call attention to the vast labor of decoding, translating, and transmaterializing official texts without which advanced mathematics could not proceed. ... tentative, transitory marks that try to produce new orders out of old ones (with a crucial stage of disorder in between) [Barany, 2014, p. 108]

This labour, as in the examples above, plays down the notion of genius, replacing it with the idea of detailed skilled work in developing ideas and working out possibilities. Lane [Lane, 2017] sees the blackboard as a tool for assembling and manipulating mathematical objects: by erasing and "boxing", drawing arrows and relating, the mathematician is more quickly able to discover patterns and perceive order. The blackboard thus becomes a space for envisioning possibilities and crafting structure, rather than just a space for proving and refining arguments, enabling the exploration of the embodied processes involved in picturing, intuiting and manipulating mathematical spaces. Mathematical practice becomes perceived as a set of skilled actions, habits, and bodily sensations, with the mathematician a craftsperson, skilfully using the physical tools of the mathematician, chalk and blackboard, and the intellectual tools of a variety of mathematical techniques. 
This language of craft resonates with many accounts of learning how to do mathematics, by both mathematicians and educators. Polya's famous problem solving techniques [Polya, 1945] are often presented as the "craft of discovery" or similar terms, [Davis, 1995], [Zeitz, 2006]. Tao's extensive and influential blog posts on learning mathematics [Tao, 2007] resonate with Boaler's work on growth mindset, advising mathematicians to continually refine their craft through mastery of a toolbox of techniques, both developing skill with existing tools, and acquiring new ones.

In the final section we return to writing on craft for a framing of these observations, but first we consider a new area for ethnographic enquiry, the online collaborations known as "polymath".

\section{Section 5 Crafting online collaboration}

Tao, with his fellow Fields medallist Tim Gowers and others, is responsible for "polymath", an endeavour for tackling significant mathematical problems through collective online activity: at the time of writing the sixteenth such project under way. The infrastructure consists solely of postings on a blog, with "house rules" [Polymath, 2009], established through collective discussion, designed to encourage interaction, accessibility and rapid exchange of informal ideas. These include, for example "It's OK for a mathematical thought to be tentative, incomplete, or even incorrect", "better to have had five stupid ideas than no ideas at all" and "An ideal polymath research comment should represent a 'quantum of progress'.”

Polymath is sometimes described as "crowdsourced science", though the crowd is a small and expert one. The unstructured development of the ideas through complex threading of multiple blog comments allows a variety of perspectives and serendipitous connections, with lines of enquiry, some fruitful, some not, weaving together in a manner much more akin to a novel than a conventional scientific paper.

As Gowers and Nielsen observe [Gowers, 2009]

Who would have guessed that the working record of a mathematical project would read like a thriller? [Gowers, 2009, p. 880]

Polymath is an example of a social machine, a concept due to Berners-Lee, defined as "purposeful human interaction on the web", where machines enable mass human collaboration, rather than acting as mechanical problem solving agents. Social machines cover phenomena as diverse as Wikipedia, twitter, or Zooniverse, and this enmeshed nature of contributor threads, allowing serendipitous interactions, has been identified as a powerful element of their success.

Polymath conversations rapidly become too unwieldy and interwoven to self-organise: a leader draws together the threads from time to time, suggesting the most appropriate next direction, and restarting 
the discussion with a substantial new blog post. These posts, presented in a more conventional mathematical style, then form the basis of the eventual published paper. Though all polymath projects seem to have produced something useful, not all have proved their target result, with attempts failing through finding a counter-example, or for of lack of participants or fruitful ideas. The most successful have led to published papers, under the pseudonym "D H J Polymath", where the initials refer to the Density Hales-Jewett theorem, which was the subject of the first Polymath. Participants themselves [Polymath, 2014] are aware of the complex social space thus created, for example reflecting on the opportunities and risks of collaboration behind a pseudonym, rather than a more modest sole contribution.

A recent book by Vicky Neale [Neale, 2017] presents the most notable polymath to date, which extended work of Yitang Zhang to massively reduce the bound on the so called "Twin Primes conjecture". Neale's book starts in a landscape, not Hardy's distant views of lofty peaks, but handson climbing in the manner of Ryle's jungle walks:

You stand looking at the sheer surface of your mathematical problem, searching for toeholds and crevices that might give a way up. After a long time looking, you start to make out an indistinct crack to the left, and a slight pattern in the rock up and to the right that reminds you of a climb you heard about once. Putting together all the features you've noticed, you can sketch out a possible route up the rock face, although it's not quite clear whether that small ledge will make a good toehold and there's a pretty ambitious reach near the top that might well be a stretch too far.

Still, now that you have a possible route in mind, you can step off the ground, and hope that the details will become clearer along the way. Perhaps that reach will be too big, but when you get a bit closer maybe there'll be a crack in just the right place for your fingers.

Unfortunately, when you're three-quarters of the way up a sliver of rock breaks away, your toehold disappears from beneath your feet, and you drop back some way. Eventually, however, if you persevere you might reach the top. [Neale, 2017, p. 1]

The polymath blogs display mathematical proofs, and attempts at proofs, in exactly this fashion: discussion of possible partial approaches, working through the details, resolving bottle-necks and retreating from dead-ends, perhaps by refining current techniques, perhaps by trying something new, and vividly demonstrating how advance may come from sharing and refinement of small insights, as well as from one big breakthrough. The contrast with Hardy's view of an educator's exposition of a completed proof, "rhetorical flourishes designed to affect psychology" is striking. 
By contrast with an isolated researcher working on one idea at a time, a polymath project can pursue several lines of attack simultaneously, adding to the potential for fruitful interaction at the cost of greater attention to the ideas of others. We have discussed elsewhere [Martin, 2015] how polymath, and similar mathematical social machines, shed light on the everyday practice of mathematics. We highlighted how few of the blog comments are actual steps in the final proof, with other phenomena such as examples, conjectures, concept formation, and planning, playing key roles in exploring the landscape, and indicated the importance of dead ends and mistakes in increasing understanding, and the value of collaboration in providing diverse skills, capturing mistakes and allowing more risks to be taken.

Lakatos's [Lakatos, 1976] account of the development of proofs, presented in an educational framework, seems a much tidier view, in which every action has a clear logical role in the development of the final proof, presented using a theory of responses to counterexamples. However Lakatos was providing a rational reconstruction, and, just as in an account of a successful rock-climb, pruning some of the dead-ends and abandoned lines of enquiry makes for greater readability without altering the purpose of the narrative.

The developers of "polymath" were motivated not just by finding new ways of to solve problems, but also by a strong interest in mathematical education, and in showing their readers, far more clearly than in a standard textbook or lecture, the messy day to day process of doing mathematics, as well as the final proof that emerged. Originally they had hoped to encourage newcomers to take part, an aim not entirely realised, as taking part required a level of specialist knowledge, a commitment of time, and a willingness to make mistakes in public. However, the educational value of polymath is undisputed, in showing, as Tao put it "how the sausage is made", with educators following the proofs as they developed, enabling students to see the sheer excitement of doing mathematics, as well as seeing that even top mathematicians get stuck, make mistakes and need to ask for help [Martin, 2015]. The MITbased "crowdmath" project follows the model of polymath, providing structured and mentored environment for high-school and college students to collaborate on research level problems, and has led to several published research papers [Crowdmath, 2015]. Other online experiments, in which technology is used to enhance learning outcomes include an experimental MOOC developed by Boaler et al, designed to encourage participation, interaction, and a move to a "growth mindset". It has attracted over 160,000 participants, and has been used to demonstrate correlations between this intervention and both academic achievement and attitudes towards mathematics.

\section{Section 6 Mathematics and craft}

Craft has a scholarly literature of its own, and in this final section we reflect on what it might contribute to understanding the practice of mathematics. Heidegger [Heidegger, 1962] characterised crafting as an embodied process of bringing objects/ concepts/ structures into being in the world, a 
form of skilled work by which such objects/concepts/structures are built up dynamically through encounters between the subject of the craft-person and the object which is being crafted. He argued that the distinction between subject and object is dissolved through the process of crafting, as the thing being materialised is imbued with the character and will of the craft-person.

This concept of craft is closely linked to Levi-Strauss's [Levi-Strauss, 1966] idea of bricolage (assembly, or making). Bricolage is undertaken by a bricoleur, who assembles diverse objects together into a coherent assemblage, through uniting material objects within the framework of an idea: what transforms the material assemblage of a bricolage from a mess into a craft-work is not the identification of each of the elements as isolated wholes, but rather the higher conceptual structure within which these elements are related, as part of an intentional composition by the craft-person. Mackenzie [Mackenzie, 2003] introduces the idea of mathematical practice as bricolage, which he characterises as "creative tinkering" guided by broader principles, in his work on the creation the Black-Scholes equation. In a mathematical proof it is not the individual elements which give insight, but rather their relationships within a wider discourse structure, which orients them towards a certain purpose.

As Ingold, in his work on "making" [Ingold, 2011] indicates, a deeper history of craft stretches back to the classical era, where craft or "practice" ( technê) is contrasted with knowledge or "theory" (Epistêmê). Craft is concerned with skills or practices, obtained through apprenticeship with a master craft-person, with such skills developed through practice, so they become a form of know-how or embodied knowledge and habit. In the case of mathematics, the mathematician directs their craft skills to the goal of understanding and manipulating mathematical objects. Tanswell's thesis [Tanswell, 2017] develops this in a discussion of Ryle's distinction between knowing-how and knowing-that, showing that both are necessary, and intertwined in the process of doing mathematics.

David Pye, a furniture maker and eminent scholar of craft, characterises craft as [Pye, 1968, p. 20]

simply any kind of technique or apparatus, in which the quality of the result is not predetermined, but depends on judgment, dexterity and care which the maker exercises as he works. The essential idea is that the quality of the result is continually at risk during the process of making; and so I shall call this kind of workmanship "The workmanship of risk"

He contrasts this with the "workmanship of certainty" where every step and hence the outcome is prescribed, leaving no decisions to the maker, and observes the need for both.

Much writing on craft is concerned with the physicality of tool use, the numerous small choices made in controlling a saw for example. In developing a mathematical proof the "tools" might be techniques 
or approaches: "find a minimum", "look for a bound" and so on, each requiring its own skill in application - the process of "stumbling around in the dark" so articulately described by Wiles. Processes like Wiles's "a little more calculation" are routine and certain in their outcome, the "workmanship of certainty", whereas "modifying things a bit" is more akin to the "workmanship of risk". A polymath proof development shows exactly the choices and refinements being made, as participants debate the choice of different "tools" at each stage, mitigating the "risk" by having others check or comment on their work, and sharing out the routine labour which has more "certainty", for example doing a routine calculation.

Ingold [Ingold, 2011] gives a close description of using a saw to illustrate the precessional quality of tool use, where precise phases are not delineated, but each contains the seeds of the next as part of an overall “umbrella plan", a notion similar to Alan Bundy's proof plans [Bundy, 1988], and characterises the essence of skill in such activities as "the improvisational ability of practitioners to disassemble the constructions of technology and creatively to incorporate the pieces". Ingold, and we recall here Wiles, Hardy, Ryle, du Sautoy and Neale, compares the activity to a journey:

It does not take just one step, however, to saw a plank. It takes many steps; moreover these steps are no more discrete or discontinuous than those of the walker. That is to say, they do not follow one another in succession, like beads on a string. Their order is precessional, rather than successional. In walking, every step is a development of the one before and a preparation for the one following. The same is true of every stroke of the saw. Like going for a walk, sawing a plank has the character of a journey, [Ingold, 2011, p. 53]

Ingold thinks of the craftsman as a "wayfarer", and Murray Rust and others [Murray-Rust, 2015] have identified this wayfaring as characteristic of crafting a path through the landscape of a social machine, like polymath, in terms that nicely fit Neale's climber:

a journeyer situated in a landscape, with signs which can be read, and possible directions to explore. Rather than a top-down map of the world, on which routes can be meticulously planned out, navigation is local and responsive. The wayfarer is engaged in a constant exchange with their environment, deciphering, orienting and acting. [Murray-Rust, 2015, p. 1144]

Ingold uses the term "meshwork" for the collection of paths taken, offering signs to the wayfarer, and acting as records of their passage; such paths are not a well-organised network, but in the entanglings offer new creative possibilities, much like Ryle's "ground where tracks certainly do not exist, but where, with luck, assiduity and judgement, tracks might and so perhaps will exist", which others can then follow, or the multiple paths through a space of mathematical possibilities. 
Ingold, like du Sautoy, identifies such journeys with stories:

landscape tells - or rather is - a story. ... To perceive the landscape is therefore to carry out an act of remembrance, and remembering is not so much a matter of calling up an internal image, stored in the mind, as of engaging perceptually with an environment that is itself pregnant with the past. [Ingold, 2000, p. 189]

We have but scratched the surface in this essay, and philosophers, ethnographers, social scientists, humanists, educators and scholars of craft have much to say about matters we have left unaddressed.

In our reading, Newton's beach or Hardy's Himalaya or Ryle's jungle or Wiles's cellar or Neale's cliff-face or Thomas's garden are comprehended and communicated as wayfarings in landscapes. These landscapes, as articulated by Jenkins, are metaphors for mathematicians' internal representations, themselves made of a collection proof attempts/journeys/stories, and constantly reshaped through their own new proof attempts/journeys/stories, and through learning of those of others. Ryle's distinction between knowing-what and knowing-how becomes a matter of degree rather than a matter of kind: in the most general terms Hardy surveying the distant peaks knows that there is a proof /route and convinces others, and Neale, scrambling up the rock-face, knows how to enact it. But Hardy sometimes gets his fingernails dirty, and Neale sometimes draws back and inspects the route.

For the educator, the view of mathematics as a craft activity, and of mathematical ability as a skill to be developed, rather than a fixed talent, is not new, and Tao's emphasis on continually extending one's knowledge and skills is a good antidote to unrealistic notions of genius. Activities like polymath allow learners to better understand and learn the craft of how mathematics is done through seeing others exercising those craft skills, and offer an opportunity to develop their own skills by taking part.

The knowledge and skills of both learners and established mathematicians is continually moderated by their own journeys and those of others, raising further questions as to the nature of this mathematical material that is being crafted, and in turn crafting its crafters, the mathematicians. Yet what material is as vital as mathematics, in its ability to affect change on the world, and to push back on the hands and minds of practitioners?

\section{Acknowledgements}

We thank Dave de Roure and Pip Willcocks for helpful discussions, and the referees for their thoughtful comments. Support from the UK Engineering and Physical Sciences Research Council is acknowledged under grants EPSRC EP/K040251/2 (Martin, Lane, Tanswell), EP/J017728/2 (MurrayRust) and EP/P017320/1 (Pease). 


\section{Bibliography}

[Barany, 2014] Barany, M, Mackenzie, D. Chalk: Materials and Concepts in Mathematics Research. pp. 107-130 Representation in Scientific Practice Revisited. MIT Press 2014

[Boaler, 2016] Boaler, J. Mathematical Mindsets: Unleashing Students' Potential Through Creative Math, Inspiring Messages and Innovative Teaching. San Francisco, CA: John Wiley \& Sons, 2016 [Bourdieu, 1984] Bourdieu, Pierre, Distinction: A Social Critique of the Judgement of Taste, tr. Richard Nice, Harvard University Press, 1984

[Bourdieu, 1985] Bourdieu, Pierre, The Social Space and the Genesis of Groups. Theory and Society, $14,723-744,1985$

[Bundy, 1988 ] Bundy, Alan, The use of explicit plans to guide inductive proofs, International Conference on Automated Deduction, 1988

[Calegari, 2017] Calegari, Frank, galoisrepresentations.wordpress.com/2017/12/17/the-abcconjecture-has-still-not-been-proved/

[Crowdmath, 2015] https://artofproblemsolving.com/polymath

[Davis, 1995] Davis P J and Hersh, R The Mathematical Experience, study edition, Birkhauser 1995

[De Morgan, 1842] De Morgan, Augustus. The Differential and Integral Calculus, Baldwin and Cradock, 1842, p vii

[du Sautoy, 2015] du Sautoy, Marcus, How mathematicians are storytellers and numbers are the characters, The Guardian 23 January 2015

www.theguardian.com/books/2015/jan/23/mathematicians-storytellers-numbers-characters-marcusdu-sautoy

[Dweck, 2006] Dweck, C. S. Mindset: The New Psychology of Success. New York, NY: Random House Incorporated, 2006.

[Ehrhardt, 2010] Ehrhardt, Caroline, A Social History of the "Galois Affair" at the Paris Academy of Sciences, Science in Context, 23(1), 2010, p. 91-119.

[Gowers, 2000] Gowers, Timothy, The Two Cultures of Mathematics, in Mathematics: Frontiers and Perspectives, edited by Vladimir Igorevich Arnol'd, AMS 2000

https://www.dpmms.cam.ac.uk/ wtg10/2cultures.pdf

[Gowers, 2009] Gowers, T, Nielsen, M. Massively Collaborative Mathematics, Nature 461, 879- 881 (2009)

[Hardy, 1929] Hardy, G H, Mathematical Proof, Mind 1929

[Harris, 2015] Harris, Michael, Mathematics without Apologies, Princeton, 2015

[Heidegger, 1962] Heidigger, Martin Being and Time, tr J. Macquarrie and E. Robinson. Harper \& Row, 1962.

[Hollings et al, 2017] Hollings, Christopher; Martin, Ursula; Rice, Adrian The Lovelace-De Morgan Mathematical Correspondence: A Critical Re-appraisal, Historia Mathematica, Volume 44, Issue 3, 2017, Pages 202-231

[Ingold, 1993] Ingold, Tim The Temporality of the Landscape. World archaeology, pages 152-174, 1993.

[Ingold, 2007] Ingold, Tim Lines: A Brief History. Taylor \& Francis, 2007.

[Ingold, 2010] Ingold, Tim The Perception of the Environment: Essays on Livelihood, Dwelling and Skill. Psychology Press, 2010.

[Ingold, 2011] Ingold, Tim Being Alive: Essays on Movement, Knowledge and Description. Taylor \& Francis, 2011.

[Jenkins, 2007] Jenkins, Alice Space and the 'March of Mind': Literature and the Physical Sciences in Britain 1815-1850, OUP 2007

[Lakatos, 1976] Lakatos, I. Proofs and Refutations. Cambridge University Press, Cambridge, 1976.

[Lane, 2017] Lane, Lorenzo. PhD Thesis, University of Edinburgh, 2017

[Levi-Strauss, 1966] Levi-Strauss, Claude The Savage Mind. University of Chicago Press, 1996 [Mackenzie, 2003] Mackenzie, D An Equation and its Worlds, Bricolage, Exemplars, Disunity and Performativity in Financial Economics, Social Studies of Science 33, 831-868 (2003) 
[Martin, 2015] Martin, Ursula Stumbling Around in the Dark: Lessons from Everyday Mathematics, Proceedings of CADE-25, Ed A.P. Felty and A. Middeldorp, Lecture Notes in Artificial Intelligence, 9195, Springer 2015

[Mason, 2016] Mason J, and Hanna, G. Values in Caring for Proof, in Mathematical Cultures, ed B Larvor, Springer Trends in the History of Science, 2016

[Murray-Rust, 2015] Murray-Rust, Dave et al, On Wayfaring in Social Machines, Proc of the 24th Int Conf on the World Wide Web, 1143-1148 (2015)

[Neale 2017] Neale, Vicky Closing the Gap, The Quest to Understand Prime Numbers, Oxford University Press, 2017

[Polya, 1945 ] Polya, G How to solve it, Princeton University Press, 1945

[Polymath, 2014] Polymath, D H J The 'bounded gaps between primes' polymath project: a retrospective analysis'. Newslett. Eur. Math. Soc. 94, 13-23

[Pye, 1968] Pye, David. The Nature and Art of Workmanship, Cambridge University Press, 1968

[Roberts, 2015] Roberts, Siobhan. John Horton Conway, the world's most charismatic mathematician, The Guardian, 23 July 2015 www.theguardian.com/science/2015/jul/23/john-horton-conway-themost-charismatic-mathematician-in-the-world

[Robinson, 2011] Robinson, Andrew. Genius, a very short introduction, Oxford University Press, 2011

[Ryle, 1971] Ryle, Gilbert. Thinking and Self-Teaching, Journal of Philosophy of

Education 5, 216-228

[Schaffer, 2009] Simon Schaffer, Newton on the Beach: the Information Order of Principia

Mathematica, Hist. Sci., xlvi Science History Publications Ltd. (2009)

[Sewell, 1992] Sewell, W H, A Theory of Structure: Duality, agency, and transformation. American Journal of Sociology, 98, 1-29, 1992

[Tanswell, 2017] Tanswell, Fenner Proof, Rigour \& Informality: a Virtue Account of Mathematical Knowledge, PhD, University of St Andrews, 2016

[Tao, 2007] Tao, Terry, Does one have to be a genius to do maths? terrytao.wordpress.com/careeradvice/does-one-have-to-be-a-genius-to-do-maths/

[Tao, 2017] Tao, Terry. Blog comment on "The ABC conjecture has (still) not been proved" galoisrepresentations.wordpress.com/2017/12/17/the-abc-conjecture-has-still-not-beenproved/\#comment-4563

[Thomas, 2016] Thomas, Robert Beauty Is Not All There Is to Aesthetics in Mathematics,

Philosophia Mathematica, 25, 116-127, 2017

[Turnor, 1806] Edmund Turnor, Collections for the history of the town and soke of Grantham (London, 1806), 173 n. 2, where it is claimed this was said by Newton "a little before his death". [Villani, 2015] Villani, Cedric. Birth of a Theorem: A Mathematical Adventure, Farrar, Straus and Giroux, 2015

[Wiles 2000] Wiles, Andrew, Transcription of interview by PBS, 2000

www.pbs.org/wgbh/nova/physics/andrew-wiles-fermat.html

[Zeitz, 2006] Zeitz, P The Art and Craft of Problem Solving, Wiley, 2006 